\title{
Future Preparedness and Futures Literacy Needs in Large Enterprises: A Regional Pilot Study
}

\author{
Lukasz Nazarko ${ }^{1 *}$ \\ ${ }^{1}$ Faculty of Engineering M anagement, Bialystok University of Technology, Wiejska 45A, \\ 15-351 Bialystok, Poland
}

\begin{abstract}
Future preparedness in enterprises is seen as an important factor affecting their performance and long-term survival. Different organisations present various approaches to reflecting on alternative future visions of their businesses. They are also characterised by different styles of translating those reflections into action with the aim of achieving a desirable version of their future. The paper presents the results of research which aimed at exploring how large Polish, mostly industrial, enterprises reflect on their long-term future. It also attempts to answer the question on the need for fostering futures literacy in Polish business milieu. The research fills in the gap in the study of future orientation of the Polish enterprises and it may be a starting point for the more in-depth qualitative and quantitative investigations. The study has been carried out on a sample of large enterprises in Podlaskie V oivodship, Poland.
\end{abstract}

Keywords: future preparedness, future orientation, foresight, industry, enterprise

\section{Introduction}

The ability to properly analyse signals and trends has paramount importance for competitiveness and survival of companies. Looking into the long term future of a business ( 5 years and more) is becoming increasingly difficult as the economic, social, technological and political systems are becoming more complex and dynamic.

This paper present selected results of a study of large enterprises in Podlaskie Voivodship, Poland. The research concerning change management, relations with labour market institutions, organisational culture and future orientation. This work focuses on the last aspect of the research: future orientation and future preparedness of large enterprises in the Podlaskie region.

In this paper, future preparedness is understood as a combination of the following elements:

* Corresponding author: l.nazarko@ pb.edu.pl 
- $\quad$ Foresight competencies of managers [1-3]

- $\quad$ Foresight maturity of the enterprise [4,5]

- Coherent strategic orientation (often expressed in a form of a document)

The research design aimed at shedding some light of the three above mentioned aspects of future preparedness.

\section{Methods and Data}

The study covered 34,5\% of large companies in Podlaskie Voivodship (29 out of 84) [6]. The questioned entities represented industry (20 enterprises), construction ( 2 enterprises), transportation (3 enterprises), commerce ( 2 enterprises) and other sectors (2). The respondents were either owners/CEOs of the enterprises or represented companies' highlevel management. 17 of them were men, 12 were women. The age distribution of the respondents is illustrated in Fig. 1.

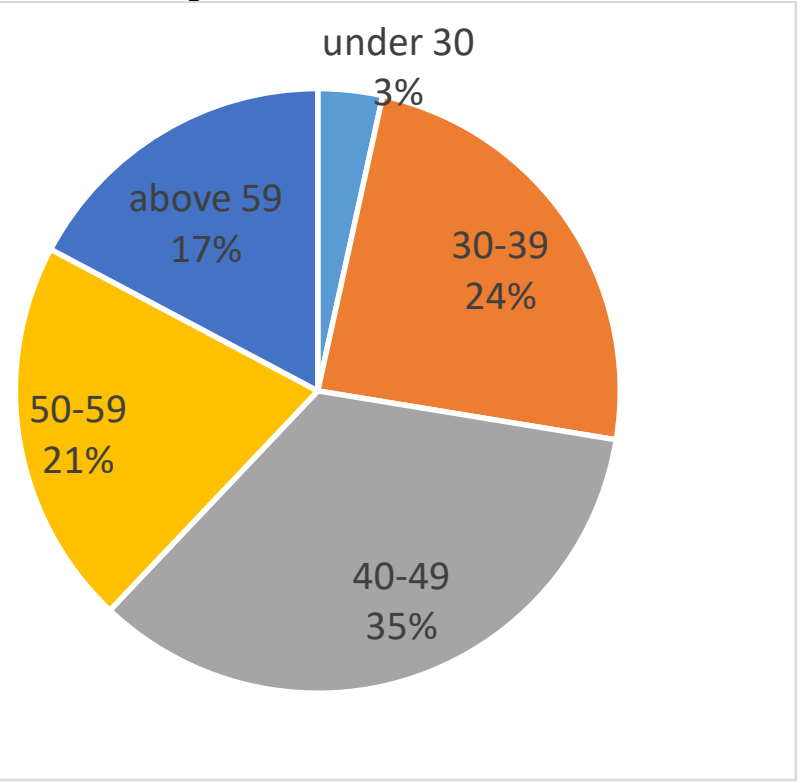

Fig. 1. Age distribution of the respondents.

The research tool consisted of a questionnaire filled in by the respondents. This paper analyses the answers given to the following questions:

1. Does the enterprise have a strategic document? (possible answers: yes; no). If yes, what is its time horizon?

2. Who is responsible for the exploration and understanding of the changes emerging in the enterprise's environment? (possible answers: Chairman/CEO/Board; assigned staff; external entities; other)

3. Has there been an event in the past when an unexpected change had a significant impact on the functioning of the enterprise? (possible answers: yes; rather yes; hard to say; rather no; no)

4. From today's perspective, would that change could have been foreseen? (possible answers: yes; rather yes; hard to say; rather no; no)

5. From today's perspective, was the enterprise able to prepare for that change? (possible answers: yes; rather yes; hard to say; rather no; no) 
6. Has there been an event in the past when the enterprise gained an advantage over competitors thanks to a better/faster exploration of the incoming change in the enterprise's environment? (possible answers: yes; rather yes; hard to say; rather no; no)

7. Is there a need in your enterprise to train the employees in the field of exploring the changes emerging in the enterprise's environment and in responding to those changes? (possible answers: yes; rather yes; hard to say; rather no; no)

\section{Methods and Data}

The first question that probed the enterprise's attitude towards long term future was the question related to the existence (or non-existence) of a formal strategy laid down in an official corporate document. It turned out that $79 \%$ of studied companies had such a document. The most common time horizon of those strategies was 5 years (11 cases), the maximum horizon was 10 years ( 2 cases), the minimum horizon was 1 year.

The second question related to the issue of a foresight culture in the studied enterprise. Its aim was to verify who in the company is engaged forward-looking thinking and in the analysis of the identified trends. Most of the questioned enterprises (79\%) pointed at the CEOs and Board of Directors as the sole actors responsible for the exploration and understanding of the changes emerging in the enterprise's environment. In two cases the $\mathrm{CEO} /$ Board of Directors were supported in this task by additional staff. In three cases it was only assigned staff that took charge of the future-oriented reflection in the company. None of the respondents used external services (e.g. professional foresight consultants) to support them in improving their future resilience.

Another two questions related to the actual utility of foresight exercises in business. Respondents were asked whether they had encountered unexpected events that had a significant impact on the functioning of their enterprise and, if yes, whether - from today's perspective - would change could have been foreseen and prepared for. The answers to the first part of the question are presented in Fig. 2.

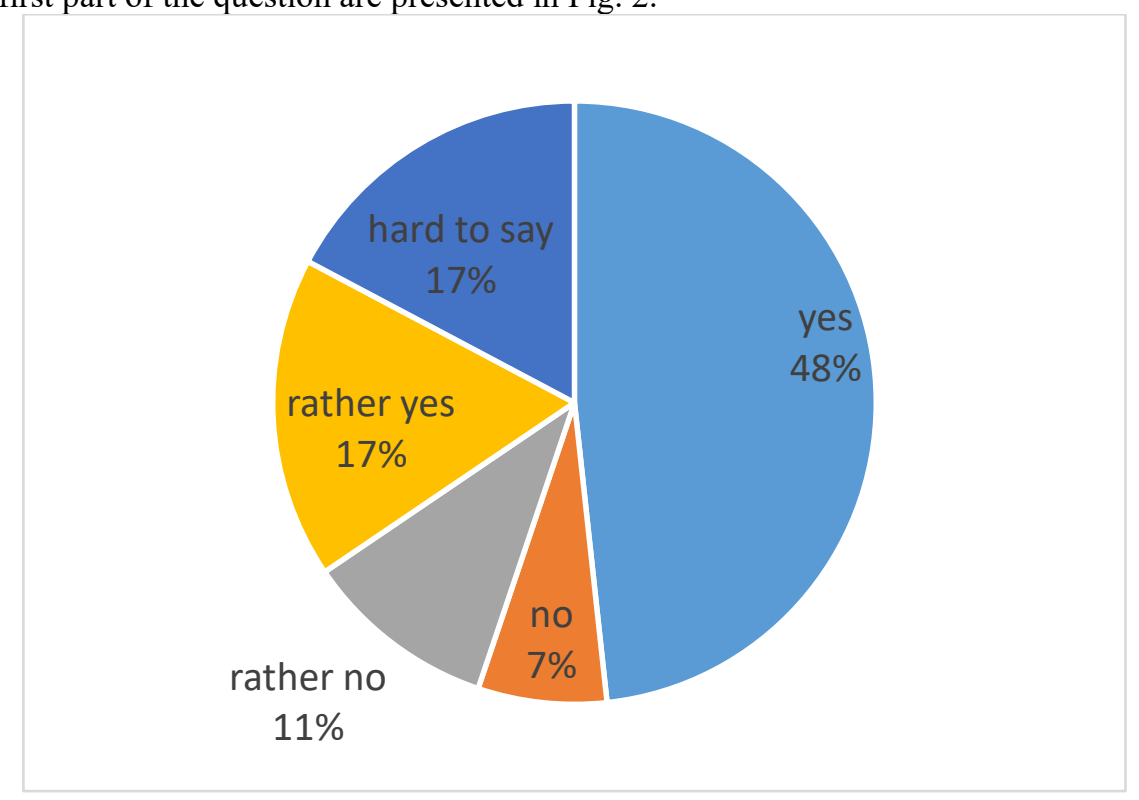

Fig. 2. Answers to the question "Has there been an event in the past when an unexpected change had a significant impact on the functioning of the enterprise? 
The answers given to that questions are mixed, however, $65 \%$ of company leaders confessed they had indeed been in the past surprised by new developments in the environment of their business. More than a quarter does not have a clear opinion on that matter. $18 \%$ of the respondents claim that such events had not occurred.

Among those who feel they had been surprised in the past, some respondents (32\%) claim that the surprising and impactful event could have been anticipated. $42 \%$ of the interviewed business leaders claim that nothing could have been done anyway to anticipate the emerging situation. Details of the answers to that question are presented in Fig. 3.

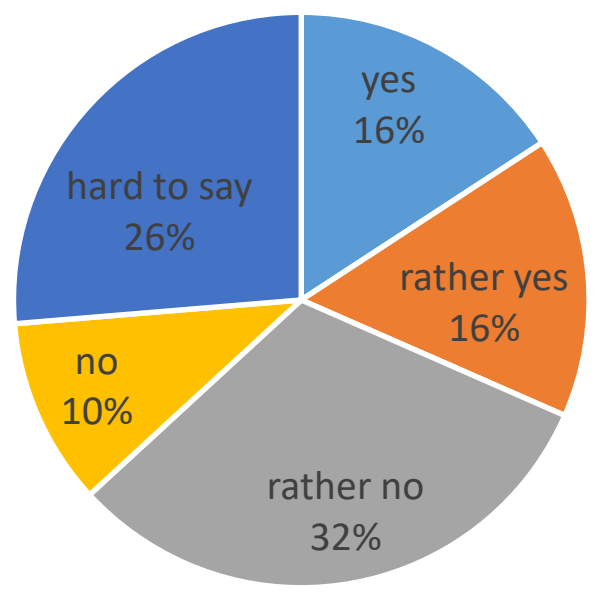

Fig. 3. Answers to question "From today's perspective, would that change could have been foreseen?"

Another linked question concerned the issue of the future resilience of the enterprises i.e. their ability to prepare and respond to the incoming change. The managers responded to the question whether they felt that their company had been able to prepare for the incoming change had it noticed and understood it early enough. Fig. 4 is an illustration of the respondents' opinion on that. 


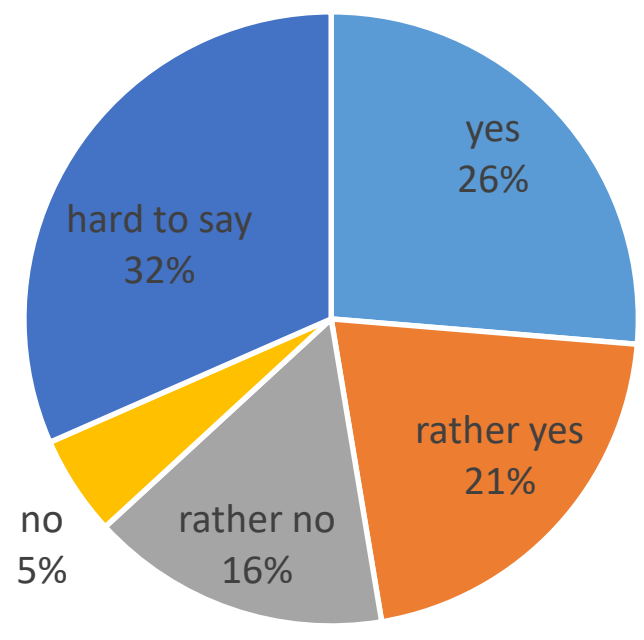

Fig.4. Answers to question "From today's perspective, was the enterprise able to prepare for that change?"

Almost half of the respondents were convinced that their enterprise had been indeed able to do something to prepare for the incoming change. $21 \%$ claim there was nothing they could do anyway. One-third of the questioned managers didn't have a clear opinion on that issue.

Next question aimed at verifying enterprises' foresight capabilities against their market success [7-10]. Respondents were asked if there had been an event in the past when the enterprise gained an advantage over competitors thanks to a better/faster exploration of the incoming change in the enterprise's environment. The answers are presented in Fig. 5.

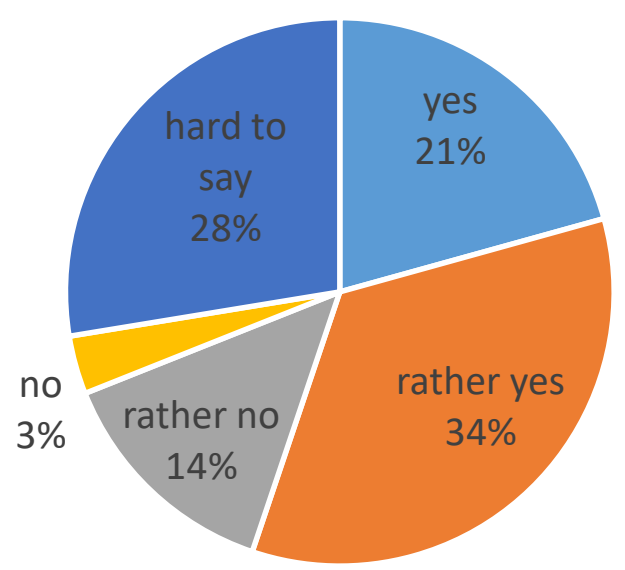

Fig. 5. Answers to the question "Has there been an event in the past when the enterprise gained an advantage over competitors thanks to a better/faster exploration of the incoming change in the enterprise's environment?" 
More than half of the respondents believe that better foresight capabilities of their companies gave them a considerable market handicap. Only $17 \%$ of the interviewed business leaders don't subscribe to that statement.

In the final question, the issue of developing foresight competencies in the enterprises was raised. The respondents were asked if they saw the need for increasing the knowledge of foresight methodology and practical foresight skills in their companies [11]. The results are presented in Fig. 6.

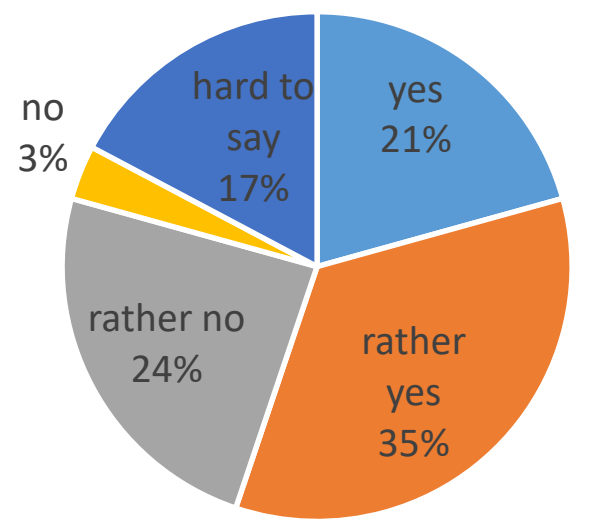

Fig. 6. Answers to question "Is there a need in your enterprise to train the employees in the field of exploring the changes emerging in the enterprise's environment and in responding to those changes?"

Again, more than half of the respondents were keen on engaging their employees in systematic training increasing their futures literacy. About a quarter of the respondents didn't see such needs in their companies.

\section{Conclusions}

The study covered about one-third of large enterprises in the Podlaskie region, hence its results may be treated as a good indication of prevailing trends in that population. The research allowed to understand better the level of future preparedness of the selected group of companies. The growing body of research [12] suggest the usefulness and effectiveness of foresight tools in the strategic management of companies of different sizes. It seems that the foresight potential is not fully appreciated and utilised among large companies in Podlaskie Voivodship.

Directions of future research are multiple. There is a clear need to map the foresight competencies and needs of enterprises on different levels and in different dimensions. Research on both regional and country-wide scale may shed light on differences between the level of foresight competencies among enterprises located in regions of different socioeconomic development levels and different business cultures. That, in turn, could lead to interesting comparative international studies. 


\section{References}

1. M . A msteus, M anagerial foresight: M easurement scale and estimation, Foresight 13(1): 58-76 (2011)

2. S. Kinkel, B. Schemmann, and R. Lichtner, Critical Competencies for the Innovativeness of $V$ alue $C$ reation Champions: Identifying Challenges and W orkintegrated Solutions, Procedia Manufacturing 9: 323-330 (2017)

3. A. Kononiuk, A. Sacio-Szymańska, and A. Gáspár, How do companies envisage the future? Functional foresight approaches, Engineering Management in Production and Services 9(4): 21-33 (2017)

4. R. Rohrbeck, Corporate Foresight: Towards a M aturity M odel for the Future Orientation of a Firm (Physica-V erlag HD, 2010)

5. Ł. Nazarko, Cele i funkcje badań foresightowych w małych i średnich przedsiębiorstwach, Studia Ekonomiczne. Zeszyty Naukowe Uniwersytetu Ekonomicznego w Katowicach 229: 121-132 (2015)

6. Statistics Poland, http://www.stat.gov.pl

7. R. Rohrbeck, and M .E. K um, Corporate Foresight and its Impact on Firm Performance: A L ongitudinal A nalysis, Technological Forecasting and Social Change 129: 105-116 (2018)

8. J. Ejdys, and Ł. Nazarko, Foresight gospodarczy - instrumentem orientacji na przyszłość, Prace Naukowe Uniwersytetu Ekonomicznego we Wrocławiu 340: 651-664 (2014)

9. J. Nazarko, and E. Chodakowska, M easuring productivity of construction industry in Europe with Data Envelopment A nalysis, Procedia Engineering 122: 204-212 (2015)

10. J. Nazarko, and E. Chodakowska, L abour Efficiency In Construction Industry In Europe Based On Frontier M ethods: Data Envelopment A nalysis A nd Stochastic Frontier A nalysis, Journal Of Civil Engineering And Management 23(6): 787-795 (2017)

11. A. K ononiuk, A.E. Gudanowska, and K. Dębkowska, The A pplication of Cluster A nalysis in the Selection of K ey Competences of Future-O riented Entrepreneurs, CID Conference 2019 - International Scientific Conference on Collaborative Innovation Development, Poland, Bialystok, Poland, 10-11 J une 2019

12. J. Nazarko, J. Ejdys, K. Halicka, A. M agruk, L. Nazarko, A. Skorek, A pplication of Enhanced SW OT A nalysis in the Future-oriented Public M anagement of Technology, Procedia Engineering 182: $482-490$ (2017) 